\title{
A research of chimney effects of fire field in a parking tower fire
}

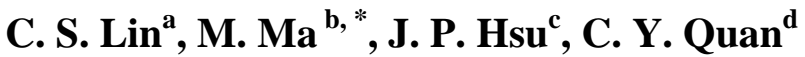 \\ Department of Mechanical Engineering, Yuan Ze University \\ amecslin@saturn.yzu.edu.tw, c groundtree889@gmail.com, ${ }^{\mathrm{d}}$ s1025129@mail.yzu.edu.tw \\ b, ${ }^{*}$ s1058704@mail.yzu.edu.tw
}

Keywords: Fire Dynamics; Numerical simulation; Stack effect; Parking tower fire

\begin{abstract}
Taiwan has significantly varying terrains, and majority of its population centralize in the plain area, where most cities are located. Most buildings here are for both commercial and residential use, and they are expanding upward in order to make use of the space better. In such high-rise buildings, parking towers are designed to facilitate parking space for vehicles. This case uses a computer numerical simulation method to simulate the expansion of a fire inside a stereo parking tower in Taipei, Taiwan. It replicates the situation of how the fire starts and studies the effects of temperature, smoke, CO concentration, and the flow of heat generated in the fire field. The results of this study can not only provide a reference to relevant companies for fire prevention design and to select fire facilities for a common parking tower but also help to arise security awareness among people who enter the parking towers.
\end{abstract}

\section{Introduction}

Taiwan is mainly a hilly terrain, where most utilizable lands are centralized in densely populated cities. Due to the rapid development of cities, especially with the limited land resources, buildings have to expand upward to cope with the shortage of space. If a fire breaks out in such skyscrapers, due to the chimney effects, the fire may result in heavy casualties. Due to the soaring population in the cities, the need of parking space is ever increasing, which motivates to create a parking tower design that make use of the space better. A vertical space is needed for the vehicles to be transported upwards to the parking tower. This vertical space designed for transportation resembles a chimney, which could facilitate a chimney effect [1-3] in case of a fire in the parking tower. The chimney effect can also lead to a rapid spreading of the fire, thus causing heavy losses if rescue is delayed. Therefore, a fast control of the spreading of fire in a parking tower fire is urgently required. In this study, an enclosed, tall building (parking tower), which could form a chimney effect when it catches fire, was used for the analysis. The chimney effect is generated by buoyancy-driven gas flow through a chimney, where the air moves upward or downward in a space with a vertical slope. Buoyancy exists because of the varying gas temperature and properties inside and outside the chimney, which enhances the air convection phenomenon. When the building catches fire, some vertical passages, such as stairways, elevator hoistways, and pipelines, may serve as vertical tubes for the smoke flow. The layer of smoke move and gather in the upper space, which facilitates the chimney effects in the fire field. Thus, as the difference in gas property and temperature becomes more significant, the buoyancy force increases, thereby increasing the chimney effects more significantly.

This study uses FDS (Fire Dynamics Simulator) [4], software developed by National Institute of Standards and Technology/Building and Fire Research Laboratory (NIST/BFRL), to simulate and analyze the hazard of the fire. Using a computer numerical simulation, a description of the buoyance-driven gas flow phenomenon can be drawn and the situation of the start of fire can be replicated. In addition, the distributions of temperature, heat radiation, CO concentration field, and the change in the generated smoke can be studied simultaneaously. FDS can provide plenty of information for fire prevention research, such as the fire motion, the spreading of smoke, heat transfer on the surfaces of fuels and walls, and the operating effects of sprinklers, which can further 
help in fire security design, such as smoke control system, sprinklers system, and sensing system. FDS is mainly based on Navier-Stokes equations, which can calculate the changes in a fluid field as well as the heat conduction induced by the fire inside buildings or in other spaces. The conservation equations are as follows:

1.Mass

$$
\frac{\partial \rho}{\partial t}+\nabla \cdot \rho \mathbf{u}=\dot{m}^{\prime \prime \prime}
$$

3. Energy

$$
\frac{\partial}{\partial t}(\rho h)+\nabla \cdot \rho h \mathbf{u}=\frac{D}{D}+\dot{q}^{\prime \prime \prime} \frac{p}{t} \dot{q}_{b}^{\prime \prime \prime}-\nabla \dot{\mathrm{q}}^{\prime \prime}+\varepsilon
$$

2. Momentum

$$
\frac{\partial}{\partial t} \rho \mathbf{u}+\nabla \cdot \rho \mathbf{u}+\nabla \mathbf{u} p=\rho \mathbf{g}+\mathbf{f}_{\mathbf{b}}+\nabla \cdot \tau_{i}
$$

4. Ideal Gas Equation

$$
p=\frac{\rho R T}{\bar{W}}
$$

\section{Overview of the fire case and model building}

East high stereo parking tower, located in $4^{\text {th }}$ lane, Zhongxiao East street, Taipei, is a 19-floor parking tower with a total height of 35.63 meters. On Nov 11, 2000, a fire accident happened; two on-duty administrators Huang and Zhang in the sentry office of East High parking tower discovered some smoke coming out of an elevator exit on the first floor. They then hurried to go out to check and were surprised to see heavy smoke coming out of the upper floor of the parking tower. They called the police immediately. The fire command center of the Taipei government received the fire report from the administrators of East High stereo parking tower at 13:03.

East High stereo parking tower is mainly for vehicle parking. The parking turntable machine is placed on the top floor; the primary structure, area, and height of the floors are shown in Table 1

Table 1 Specifications and status of East high stereo parking tower.

\begin{tabular}{|c|l|}
\hline Building height & \multicolumn{1}{c|}{35.63 meters } \\
\hline Building usable area & \multicolumn{1}{c|}{78.88 square meters } \\
\hline Building structure & $\begin{array}{l}\text { Steel frameworks, inside iron meshes painted } \\
\text { with fireproof asbestos, outside covered by } \\
\text { steel sheets }\end{array}$ \\
\hline Operating mode of the parking tower & $\begin{array}{l}\text { 2 sets of electrical turntable machine, main } \\
\text { body is the vehicle-only elevator; a vehicle } \\
\text { board is installed; the elevator is used to } \\
\text { carry the vehicle to the designated floor, and } \\
\text { then, the vehicle is driven to the designated } \\
\text { parking position; or a horizontal carry } \\
\text { machine with alternate assistance for vehicle } \\
\text { boards is used to park the vehicle to the } \\
\text { designated position }\end{array}$ \\
\hline Building features & $\begin{array}{l}\text { Tower A and Tower B are adjacent to each } \\
\text { other }\end{array}$ \\
\hline Building inner facilities & \begin{tabular}{l}
76 vehicles can be accommodated \\
\hline
\end{tabular} \\
\hline
\end{tabular}

Since the whole parking tower was an enclosed building, the fire was similar to burning in an enclosed pot; this made the building resemble a tall "chimney". The steel sheets on the external walls could not be dismantled, which aggrevated the burning inside the building. The emergency water pipes distributed by firemen could not cover the fire field directly, making the rescue even harder. Firemen had to enter the building from the exit on the first floor or use aerial ladders to enter the building from the windows on the top floor. They worked from both the top and the bottom of the building simultaneously to put off the fire, although the middle part of the building had to experience consistent internal burning for a long time, which left the whole parking lot into a sea of fire.

The simulation is conducted based on the materials collected from different departments. The relevant zones of the parking tower in the simulation are numbered as shown in Fig. 1a, and the zone division of Tower B is shown in Fig.1b. 


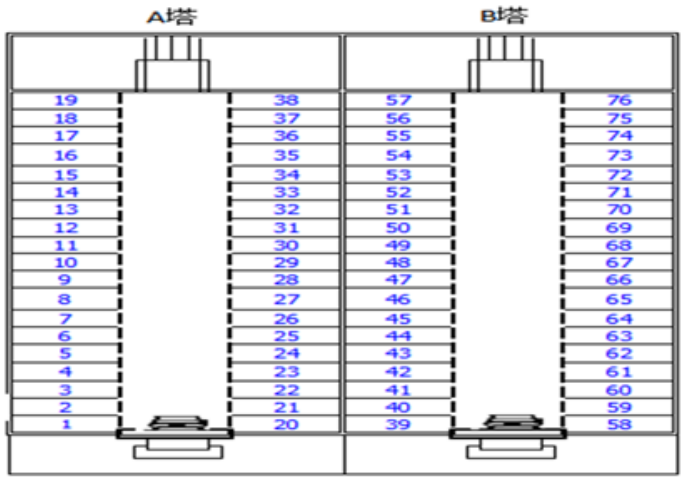

Figure 1a Simulation zone numbering for Tower A.

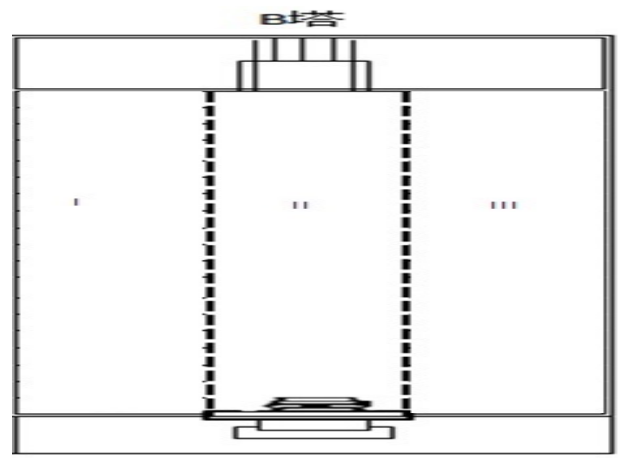

Figure 1b Simulation zone division for Tower B

\section{Simulation, verification, and analysis of the fire field}

Fire field verification 1: according to the burning test of a full-size vehicle [5], the vehicle burning (inflammables, including petroleum, cushion, plastic products, and inner decorations) facilitated the fire spreading. It takes 800 seconds for an integrated vehicle to be swallowed by the sea of fire. In the case of East high stereo parking tower, 56 vehicles were parked in different floors. The fire lasted for around 4 hours, which burnt all vehicles as well as the elevator facilities into ashes. In the simulation, the temperature reaches 1089 degrees after 750 seconds in the simulation (see Fig. 2a). It is easy to judge that the temperature in the parking tower at that moment would be extremely high, and the vehicles that have been burnt completely drop to the exits (see Fig.2b). Thus, the simulation results are close to the actual fire field. Moreover, by comparing the temperature distributions inside the parking tower, it can be seen that the temperatures in the upper floors are also very high (see Fig.2c), which result in severe damage or even total burn-off of all vehicles.

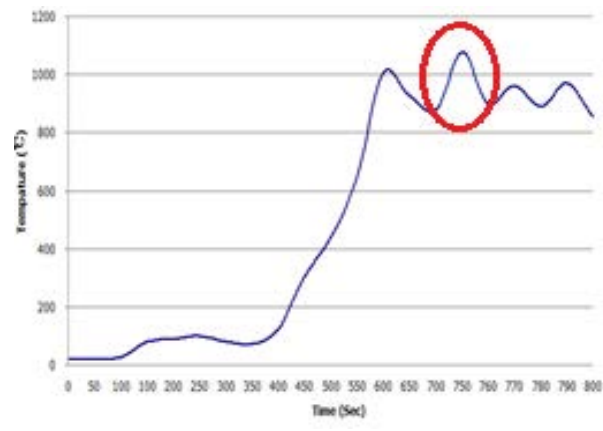

Figure 2a Temperature distribution inside the tower at $750 \mathrm{~s}$

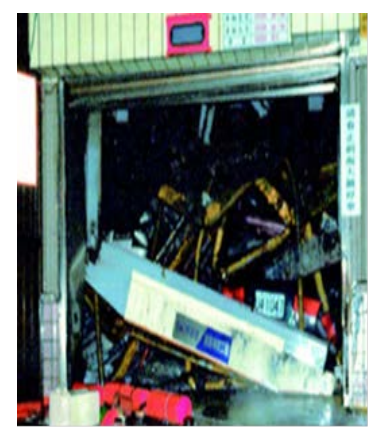

Figure 2b Picture of burn -off cars.

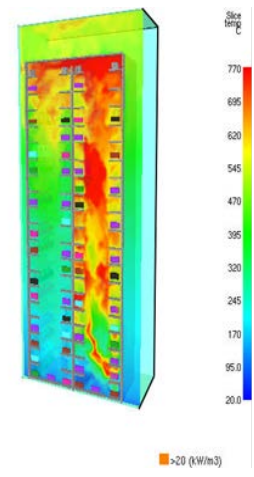

Figure 2c Temperature

Profiles on the cross section

Of the parking tower .

Fire field verification 2: according to newspapers and magazines, when the firemen arrived at the spot, a great amount of heavy smoke was coming out of 2 windows on the top floor (see fig.3a). According to the simulation results in fig.3b, the smoke layer height decreases to half of the parking tower height at around $250 \mathrm{~s}$, so the parking tower is full of heavy smoke at that time; this is quite close to the real fire field. In addition, by comparing the transient fire fields in fig.4a and fig.4b with the real fire fields, it can be seen that the results are also quite close. Since the fire is starting from the right side, the vehicles on the right side are the first to be heavily damaged. 


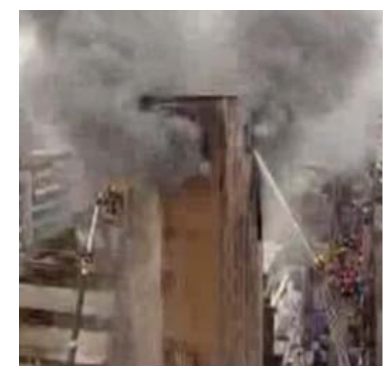

Figure 3a Smoke out of the ventilation Windows on the top floor

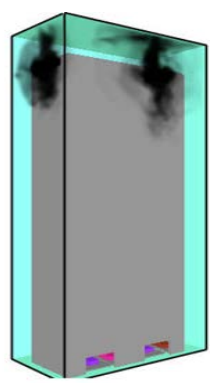

Figure 4a Transient profile of Smoke at around 100-200s

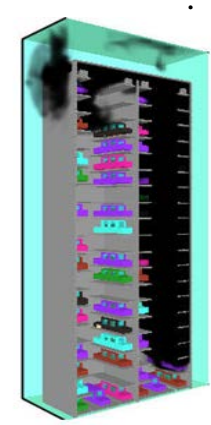

Fig.4b Cross sectional view of the transient smoke profile along the $\mathrm{X}$-axis

(X:5.8)

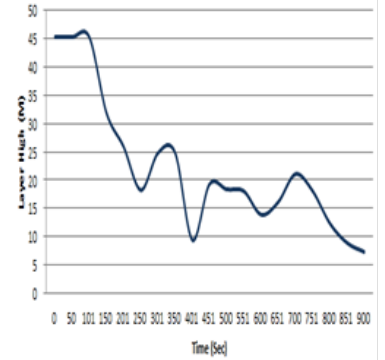

Figure 3b The distribution of smoke layer height.

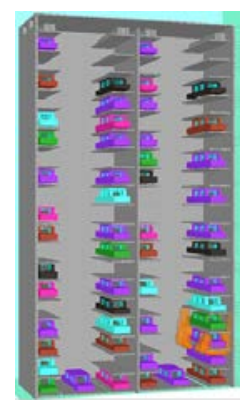

Fig4c Position of the fire source

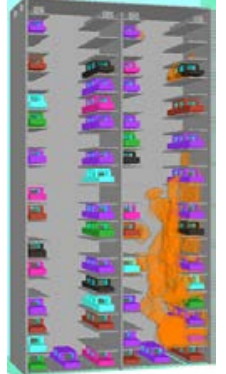

Fig4d Vertically burning fire field

\section{Results and discussion}

Using a case of fire incident in a 20-story-high stereo parking tower, this study simulated the fire field in the building. The source of fire is on the second floor, west side of the parking tower, so the simulation results of the fire source location on the second floor (fig.4c) is the focus of discussion. The parking tower is a tall and enclosed building covered by steel sheets, so the chimney effect is formed in the building, as shown in fig.4d. On the top of the tower, strong wind blows away the heated air flow, which drags the heated air to go upwards and ignite the petroleum in vehicles on each floor. With the burning of petroleum, the heated air inside the vehicles expands rapidly and leads to explosion of the vehicles. This explosion was the reason for the sound heard from the parking tower from time to time. In addition, the water sprayed by the firemen was also blown away from the effective extinguishing zone by the strong wind, making the rescue even harder. We will demonstrate the simulation results and discussions of original fire field from following four aspects:

\subsection{Discussion of smoke flow}

As the parking tower is a tall and enclosed building covered by steel sheets and the smoke passage is vertical, the chimney effect of the fire field could happen when the building catches fire. The upward air streams acceerates the fire spreading, which results in a greater fire scale. The parking tower was an enclosed, steel sheet house, which caused extreme increase in temperature, thus preventing firemen from entering it. Firemen could only splash the water from outside, but the strong wind made the rescue even harder as it blew the water away. The post-vehicle burning stage follows a theoretic model, as shown in fig.5a and fig.5b; the direction and the velocity field of the heavy smoke can be clearly verified. 


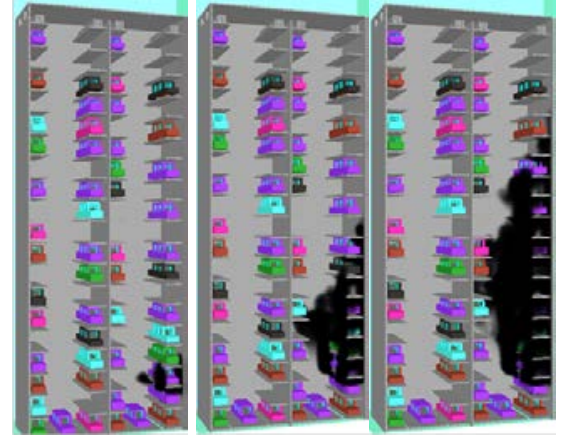

Fig.5a Simulation result of upward smoke stream from the base case

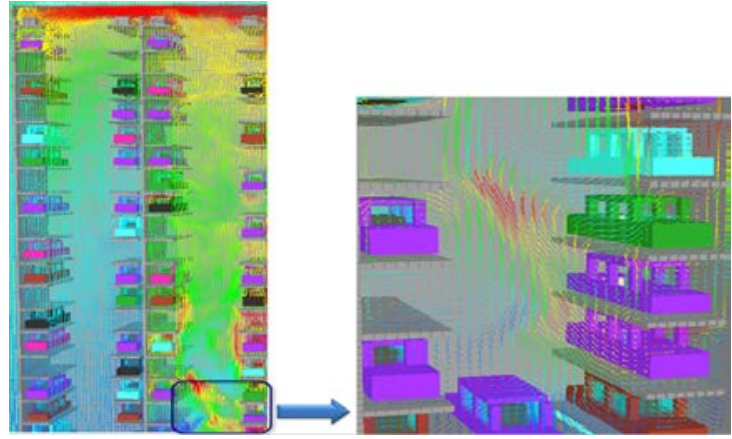

Fig.5b Simulation result of the smoke's velocity and direction from the base case

\subsection{Discussion of the temperature in the vehicle parking floors}

Since the fire source is on the second parking floor (see Fig6a), its temperature is higher than other zones (see Fig6b). The skeptical source of the fire was an unsettled engine, which caused a small fire at 35 seconds. According to literature [6], the firing point of petroleum is $280^{\circ} \mathrm{C}$. In this case, the fire source (vehicle) reaches the firing point at $171 \mathrm{~s}$, which continues to spread and heat up to $600{ }^{\circ} \mathrm{C}$, the maximum temperature, at $600 \mathrm{~s}$. Afterwards, as the time goes by and due to the shortage of inflammables, the temperature declines. And at the end of the simulation (900 s), the temperature is still around $200{ }^{\circ} \mathrm{C}$.

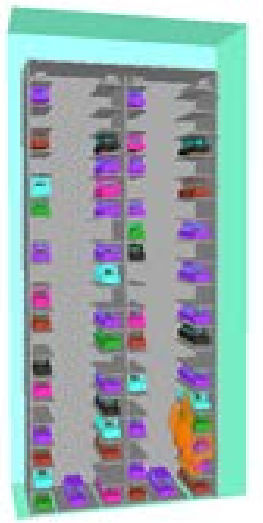

Fig. 6a Transient profile of fire flow at $171 \mathrm{~s}$

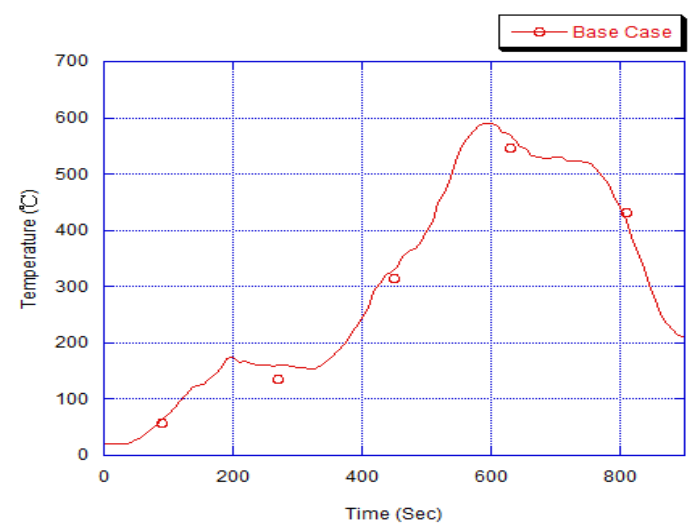

Fig.6b Temperature of the second parking floor

After $135 \mathrm{~s}$, fire spreads from its source to No. 61. Due to the high temperature and the heavy smoke, No. 61 continues to heat up after $370 \mathrm{~s}$, and at $900 \mathrm{~s}$, flares splash out of the building because the steel sheets on the external walls are deformed due to the high temperature. Figs.7a and $7 \mathrm{~b}$ are the transient temperature profiles of the fire flow.

By $900 \mathrm{~s}$, the temperature of the top floor is close to $700{ }^{\circ} \mathrm{C}$, the heated air spreads from the top of Tower A to lower floors via the voids between Towers A and B. As the heated air flow upwards, the cool air enters the building via the exit on the first floor, which provides consistent oxygen to facilitate the burning. The temperatures on each floor (excluding -F) reaches the firing point of petroleum, so the sound of explosion is constantly generate from the building. 


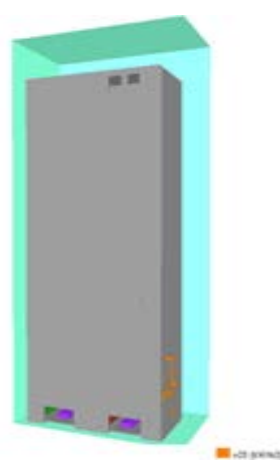

Fig.7a Fire flow on the steel-sheet external walls of $2 \mathrm{~F}$ (the original fire field) at $900 \mathrm{~s}$

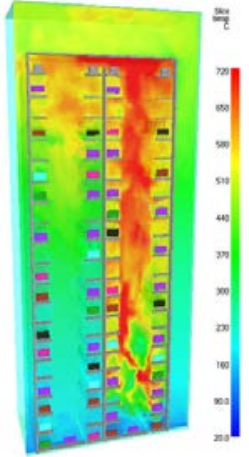

Fig.7b Temperature profile at $900 \mathrm{~s}$

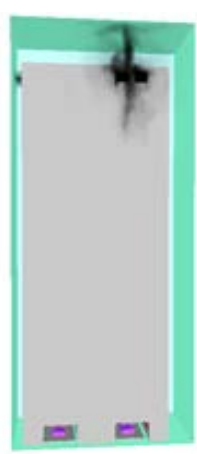

Fig7c Transient smoke flow graph of CO concentration spreading from fire source after $94 \mathrm{~s}$

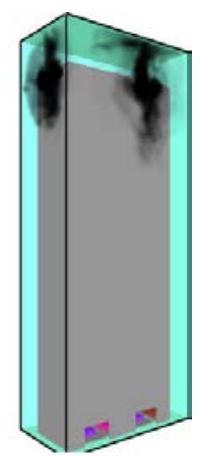

Fig7d Transient smoke profile at around 100 s to 200 s

\subsection{Discussion of $\mathrm{CO}$ concentration}

Since No. 59 is the fire source, the concentration of CO generated by the smoke of the burning also increases rapidly. The status of smoke flow in the fire source of Zone III reaches $556 \mathrm{ppm}$ and continues to increase at around $480 \mathrm{~s}$, which is high enough to be toxic to human beings. The CO concentrations in the nearby zone, Zone II, also reaches approximately $129 \mathrm{ppm}$, while the CO concentration in Zone I, which is quite far from fire source but is starting to be influenced by the fire spreading, is around 117ppm. As No. 59 is the fire source, the CO concentration as well as the accumulation is the highest in this area; CO concentration soars to $10000 \mathrm{ppm}$ in a very short time, which is high enough to cause immediate death of human beings. By $94 \mathrm{~s}$, there is smoke plume above the top of the parking tower (see figs.7c and 7d). The CO concentration of each floor experiences a linear growth when the smoke spreads upward. The smoke fills Tower B rapidly and hinders the visibility. According to the curve shown in fig.8a, CO concentrations are also very high and the accumulations are very fast in the floors above the second floor in Zone III, which reaches $1000 \mathrm{ppm}$ after $580 \mathrm{~s}$ in $11 \mathrm{~F}-19 \mathrm{~F}$. It is high enough to cause clouding of consciousness, dyspnea, coma, and convulsion in people. The $\mathrm{CO}$ concentration in other parking floors also increases consistently, depending on the distance to the fire source, which can cause threat to the life of victims and firemen.

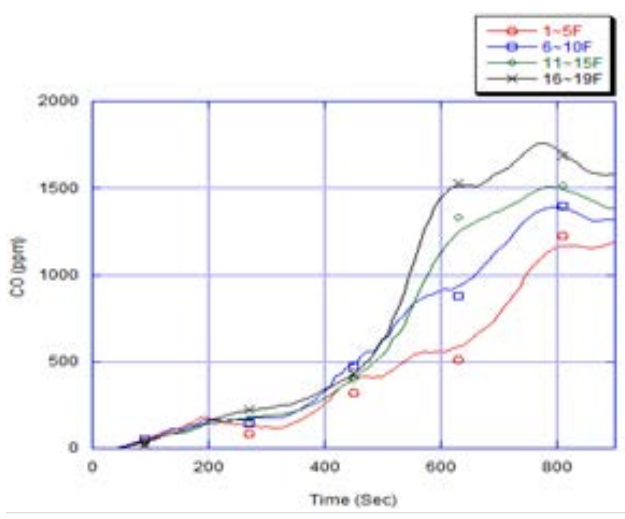

Fig.8a Vertical distributions of CO Concentration from the original fire field in Zone III

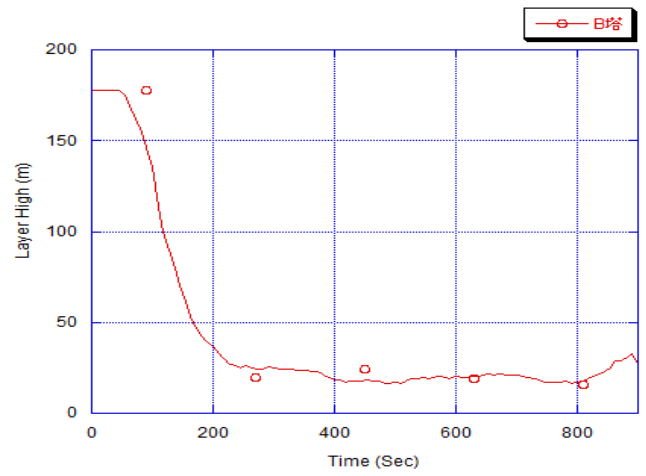

Fig.8b Smoke layer height of Tower B according to the base case

\subsection{Smoke layer height}

Fire is always accompanied with the appearance of great amount of heavy smoke; the smoke comprises some toxic gases and heated gases, which can result in aspirated wounds and lead to severe internal damage to bodies if it is inhaled by people. When the smoke layer height is far below 1 meter, it can pose an immediate threat to human body. The smoke layer height decreases when the smoke accumulates in the higher area; when the layer height decreases, the visibility also 
becomes worse, which directly affect people's evacuation possibility; this could cause panic among the escaping people and result in they losing direction to the emergency exits. At the meantime, a low smoke layer height can prevent firemen from finding the real fire source when they enter the fire field, which increases the difficulties and the potential danger of the rescue.

Fig.8b shows that even at the very beginning stage of the fire, heavy smoke may have already been generated. At $105 \mathrm{~s}$, the smoke layer height curve of Tower B drops rapidly, and the curve does not decline significantly until $400 \mathrm{~s}$ when the petroleum tank of the fire source explodes; this facilitates the burning, enlarges the burning area, and generates even more smoke. The smoke layer height drops to 10 meters after 600 seconds, heavy smoke spread through every floor from the fire source to the top of the tower. Due to the burning of inflammable matter in the vehicles, smoke of further decreased layer height is generated, which makes the rescue operation more difficult, because the possibility that someone is inside cannot be excluded.

\section{Conclusions}

A parking tower can form a chimney effect; to prevent damage to life and properties due to this chimney effect, the most important step is to guarantee fire stopping between all vertical passages and pipelines, and to not allow voids that will make the gas move horizontally. By adopting these measures, the loss can be reduced to the least. Therefore, there has to be some distance between any two floors in a parking tower, which will prevent the fire spreading and thus reduce the damage caused by the chimney effects. In addition, to prevent similar fire accidents from happening again, some fire-prevention equipment can be installed in the parking tower in the future, such as a smoke detector system, an automatic sprinkler system, and an automatic fire-resistive partition system. When the smoke detectors detect heavy smoke, the sprinklers and the fire-resistive partition turn on automatically, blocking the fire inside the floor, and at the same time, the flame is put off immediately in order to prevent the chimney effects.

\section{References}

[1] C. Stefano,S. Mijorski,”Stack Effect in High-Rise Buildings: A Review”,International Journal of High-Rise Buildings, Vol.5, No 4,pp.327-338,December 2016.

[2] P. Weismantle, L. Leung,’Burj Dubai Stack Effect-Passive Stack Effect Mitigation Meassures in the Design of the World's Tallest Building”,CTBUH Journal,Fall 2007.

[3] G. De Mey, M. Wójcik, J. Pilarski, M. Lasota, J. Banaszczyk, B. Vermeersch, A. Napieralski,M. De Paepe,” Chimney Effect on Natural Convection Cooling of a Transistor Mounted on a Cooling Fin”, Journal of Electronic Packaging,Vol.131,2009.

[4] K. McGrattan,S. Hostikka,R. McDermott,J. Floyd,C.Weinschenk,K. Overholt,” Fire Dynamics Simulator User’s Guide”,National Institute of Standards and Technology,Vol.6,2017.

[5] K. Okamoto,N. Watanabe, Y. Hagimoto,T. Chigira,R. Masano,H. Satoh,Y. Tamura,K. Hayano,Y. Maeda,J. Suzuki,’Burning behavior of sedan passenger cars”, Fire Safety Journal ,No.44,pp.301 310,2009.

[6] B. Mattsson,"The importance of the time factor in fire and rescue service operations in Sweden”,Accid. Anal. and Prev.,Vol.29,No.6,pp.849-857,1997. 
Notation

\begin{tabular}{|c|c|c|c|}
\hline Symbol & Description & Symbol & Description \\
\hline$p ; \rho ; T$ & $\begin{array}{l}\text { Pressure ; Density ; } \\
\text { Temperature }\end{array}$ & $\mathbf{f}_{b}$ & $\begin{array}{l}\text { External force vector } \\
\text { (excluding gravity) }\end{array}$ \\
\hline$R$ & Universal gas constant & $\tau_{i j}$ & Viscous stress tensor \\
\hline$W$ & $\begin{array}{l}\text { Molecular weight of the } \\
\text { gas mixture }\end{array}$ & $h$ & $\begin{array}{l}\text { Enthalpy; heat transfer } \\
\text { coefficient }\end{array}$ \\
\hline $\mathbf{u}=(\mathrm{u}, \mathrm{v}, \mathrm{w})$ & Velocity vector & $\dot{q}^{\prime \prime \prime}$ & $\begin{array}{l}\text { Heat release rate per unit } \\
\text { volume }\end{array}$ \\
\hline$m^{\prime \prime \prime}$ & $\begin{array}{l}\text { Mass flow rate of per unit } \\
\text { volume }\end{array}$ & $\dot{\mathrm{q}}^{\prime \prime} ; \varepsilon$ & $\begin{array}{l}\text { Heat flux vector } \\
\text { Dissipation rate }\end{array}$ \\
\hline $\mathbf{g}$ & gravity vector & & \\
\hline
\end{tabular}

